\title{
Magic bullets for insomnia? Patients' use and experiences of newer ( $Z$ drugs) versus older (benzodiazepine) hypnotics for sleep problems in primary care
}

\author{
A Niroshan Siriwardena, M Zubair Qureshi, \\ Jane V Dyas, Hugh Middleton and Roderick Orner
}

\author{
ABSTRACT \\ Background \\ Little is known about patients' perceptions of newer \\ hypnotics. \\ Aim \\ To investigate use, experience, and perceptions of \\ $Z$ drug and benzodiazepine hypnotics in the \\ community.

\section{Design of study} \\ Cross-sectional survey of general practice patients \\ who had received at least one prescription for a $Z$ drug \\ or benzodiazepine in the previous 6 months. \\ Setting \\ Lincolnshire, UK. \\ Method \\ Self-administered postal questionnaire. \\ Results \\ Of 1600 surveys posted, 935 (58.4\%) responses were \\ received, of which $705(75.4 \%)$ were from patients \\ taking drugs for insomnia. Of those 705 patients, \\ $87.9 \%(n=620)$ were first prescribed a hypnotic by \\ their GP, and $94.9 \%(n=669)$ had taken a sleeping \\ tablet for 4 weeks or more. At least one side effect was \\ reported in $41.8 \%(n=295) ; 18.6 \%$ wished to come off \\ hypnotic medication; and $48.5 \%$ had tried to stop \\ treatment. Patients on Z drugs were more likely to \\ express a wish to stop (22.7\% versus $12.3 \%$; odds \\ ratio $[\mathrm{OR}]=1.67,95 \%$ confidence interval $[\mathrm{Cl}]=1.13$ \\ to 2.49), or to have attempted to come off medication, \\ than those on benzodiazepines $(52.4 \%$ versus $41.0 \%$; \\ $\mathrm{OR}=1.54,95 \% \mathrm{Cl}=1.12$ to 2.12 ). The two groups did \\ not differ significantly in respect of benefits or adverse \\ effects. \\ Conclusion \\ There were no significant differences in patients' \\ perceptions of efficacy or side-effects reported by \\ those on Z drugs compared to patients taking \\ benzodiazepines. Side-effects were commonly \\ reported, which may have contributed to a high \\ proportion of responders, particularly patients on \\ Z drugs who were wishing to stop, or who had \\ previously tried to stop taking this medication. \\ Reported prescribing practices were often at variance \\ with the licence for short-term use.

\section{Keywords} \\ attitude; cross-sectional studies; hypnotics and \\ sedatives; prescriptions.
}

\section{INTRODUCTION}

Insomnia is a common, often chronic condition that increases with age and has a reported prevalence rate in Europe ranging from $4 \%$ to $37 \% .^{1,2}$ About half of those with sleep problems seek medical help, ${ }^{3}$ which often involves a prescription of hypnotic drugs including benzodiazepines like temazepam, or Z drugs such as zopiclone, zolpidem, or zaleplon. Most hypnotic prescribing takes place in primary care, and drug treatments may be inappropriately prescribed for 4 weeks or longer in up to $50 \%$ of new prescriptions. ${ }^{4}$

Over the past decade, a gradual reduction has occurred in the prescribing of older benzodiazepine hypnotics, while the use and cost of hypnotic drugs continues to rise overall. ${ }^{5}$ This has been due to fears over benzodiazepine use and abuse and an increase in prescribing of $Z$ drugs, which were marketed as safer and less liable to dependence compared with benzodiazepines. ${ }^{6}$ Zopiclone is now the most frequently prescribed hypnotic in the UK at 4 million items (39\% of items) costing $£ 10 m$ ( $43 \%$ of total

AN Siriwardena, MMedSci, PhD, FRCGP, GP, foundation professor of primary care, Faculty of Health, Life and Social Sciences, University of Lincoln; MZ Qureshi, MRCGP, GP, South Park Surgery, Lincoln. JV Dyas, BSc, DPhil, MD, PGDip HP, primary care lead, Trent Research and Development Support Unit, University of Nottingham. H Middleton, MA, MD, MRCP, MRCPsych, associate professor, School of Sociology and Social Policy, University of Nottingham, Nottingham. R Orner, BA, MSc (Clin Psych), PhD, clinical psychologist and visiting professor, University of Lincoln, Brayford Pool, Lincoln.

Address for correspondence

Professor A Niroshan Siriwardena, GP, Foundation Professor of Primary Care, Faculty of Health, Life and Social Sciences, University of Lincoln, Brayford Pool, Lincoln, LN6 7TS. E-mail: nsiriwardena@lincoln.ac.uk

Submitted: 24 November 2007; Editor's response: 5 February 2008; final acceptance: 22 February 2008

(c)British Journal of General Practice

This article was originally online first. Cite this article as: Br J Gen Pract 2008; 58: 417-422. Advance online publication. DOI: 10.3399/bjgp08X299290 


\section{How this fits in}

Little is known about patients' use, experiences, and perceptions of newer $Z$

drugs compared with older benzodiazepine hypnotics. Efficacy and side-effects

reported by those on $Z$ drugs compared with benzodiazepines were similar in

this community sample. Side-effects were commonly reported, which may have

contributed to a high proportion of participants wishing to stop or having tried

to stop taking their medication; this was significantly more likely in those on Z

drugs. Reported prescribing practices were often at variance with the licence

recommending short-term use of these drugs.

hypnotic cost). Temazepam is the next most commonly prescribed with 3.5 million items (35\%) at $£ 4 m(19 \%){ }^{7}$ As a result, over $£ 22 \mathrm{~m}$ is spent every year in primary care on 10 million items of hypnotic drugs, and these figures have shown no decline since the early 1990s. This is partly explained by an increasing population, with an average growth per year of $0.4-0.5 \%$ since 1991 and an increasing proportion of older people. ${ }^{8}$

Previous research has documented the attitudes of patients and doctors to benzodiazepines, ${ }^{9-15}$ but little has so far been published about their perceptions or experiences of $Z$ drugs, either alone or compared with benzodiazepine hypnotics. Studies of benzodiazepine hypnotics have shown that patients believe that they are more effective and safer than do doctors. ${ }^{14,15} \mathrm{~A}$ recent study of GPs showed that, compared with benzodiazepines, they believed $Z$ drugs to be safer, more effective, less liable to cause side effects, and the drugs of choice for a range of indications, ${ }^{16}$ despite a lack of evidence to support such notions. ${ }^{17}$

The clinical benefits of hypnotics have actually been shown to be small, with significant risks of complications arising from adverse cognitive or psychomotor effects, and daytime sleepiness that may persist for several months after stopping the drug. ${ }^{18}$ Such unintended reactions are reported most frequently by older patients, who are also the most likely to be prescribed the newer drugs. Complications, such as falls, fractures, and road traffic collisions, have been linked to these drugs, ${ }^{19}$ which have considerable potential for tolerance and addiction.

The aim of this community survey was to investigate and compare patients' perceptions of benefits and risks of benzodiazepines and $Z$ drugs. The study formed part of a larger investigation into methods for reducing hypnotic prescribing in primary care, and also aimed to define potential interventions for better management of sleep appropriate to the primary care setting.

\section{METHOD}

West Lincolnshire Primary Care Trust (PCT) comprised 40 general practices (now part of Lincolnshire Teaching Primary Care Trust), serving 214000 patients. Previous attempts to lower relatively high rates of hypnotic prescribing encountered resistance to change. A survey instrument was designed to collect data using a previously published questionnaire ${ }^{14}$ incorporating elements from literature searches, and discussion points raised within the project steering group, as well as advice received from experts in the field.

In 2005, forms were posted to a sample of patients on the lists of GP principals in West Lincolnshire PCT. Selection was made by each participating practice being asked to submit a list of patients who had been prescribed a Z drug or benzodiazepine taken in a single night-time dose to induce sleep in the previous 6 months. From this list of names, a random sample of 50 patients from each practice received the questionnaire for completion. The questionnaire focused on patients' attributes, views about indications for drug treatments (for example, insomnia or anxiety), and their assessment of outcomes.

Returned questionnaires were entered into a spreadsheet according to a predetermined coding frame. SPSS (version 12.1) was used for data analysis. A $\chi^{2}$ test was used for initial group correlations and logistic regression (both backward conditional and forward conditional) to analyse differences in responses for $Z$ drugs and hypnotic benzodiazepines correcting for age, sex, and duration of drug use. Analysis was restricted to patients who stated that they were taking these drugs for insomnia rather than for other indications, such as musculoskeletal pain or epilepsy. Missing data were not included in the comparisons.

\section{RESULTS}

Altogether, 935 of 1600 (58.4\%) analysable responses were received from responders who had been prescribed a benzodiazepine or $Z$ drug in the previous 6 months. Thirty-two of the 40 practices surveyed contributed patients to the survey, and the response rate from each varied considerably (mean $44.5 \%$, standard deviation $[S D]=20 \%)$. Of the responders, most (705 of $935 ; 75.4 \%$ ) were taking their drugs for insomnia rather than other indications, such as anxiety, epilepsy, or drug addiction (Table 1). Further analyses were carried out only for those confirming that they had taken drugs for insomnia. Z drugs were taken more commonly (370 of $705 ; 52.5 \%$ ) than benzodiazepines (268 of $705 ; 38.0 \%$ ), reflecting current prescribing trends. Hypnotics prescribed included zopiclone (328 responders; 46.5\%), zolpidem (39; 5.5\%), zaleplon (3; $0.4 \%)$, temazepam $(161 ; 22.8 \%)$, nitrazepam (48; $6.8 \%)$, diazepam (46; 6.5\%), or other benzodiazepines (13; $1.8 \%)$. Just over half $(50.4 \% ; 355$ of 705$)$ of responders were aged 65 years of age or older.

The majority of participants, $87.9 \%(n=705)$, were first prescribed a hypnotic by their GP, rather than a psychiatrist or other health professional. Many had been advised to continue treatment for 
longer than recommended under the licence: $45.4 \%(n=320)$ indicated they were advised to continue treatment for a month or more, and a further $42.3 \%$ ( $n=298)$ reported not being advised on treatment duration. Most responders, 92.1\% ( $n=$ 649 ), were on repeat prescriptions of hypnotics, and over two-thirds were taking hypnotics daily rather than intermittently (Table 1 ).

In a number of important respects those prescribed $Z$ drugs differed from those taking benzodiazepines (Table 2); they were more likely to be younger, to have received their first prescription from a psychiatrist, stated a wish to come off hypnotics, and made at least one attempt to come off medication. These differences were significant at $P<0.05$ (but not at $P<0.01)$. Over two-fifths of responders $(41.8 \% ; n=$ 295) reported at least one side-effect from hypnotic use. Withdrawal effects were commonly reported among those who had tried to stop their treatment, even if they were on intermittent rather than daily therapy. Responders who felt they may be at risk of becoming drug dependent were more likely to want to stop medication than those who already acknowledged dependence or felt that they were not dependent on hypnotics $(P<0.001)$.

No significant differences between $Z$ drugs and benzodiazepines were found in respect of perceived benefits or adverse effects, including withdrawal or dependence (Table 3). Almost one in five patients (18.6\% overall) expressed a desire to come off hypnotic medication. Patients on Z drugs were more likely to wish to stop (22.7\% versus $12.3 \%$; odds ratio $[\mathrm{OR}]=1.67 ; 95 \%$ confidence interval $[\mathrm{Cl}]=1.13$ to 2.49), and to have attempted to come off medication than those on benzodiazepines $(52.4 \%$ versus $41.0 \%$; OR $=1.54,95 \% \mathrm{Cl}=1.12$ to 2.12 ).

Most patients using hypnotics stated they took less time to get to sleep ( $Z$ drugs versus benzodiazepines, $76.2 \%$ versus $79.1 \%$ ), and woke less during the night (60.8\% versus $55.6 \%$ ), but half the users or fewer agreed that they slept longer (48.6\% versus $47.8 \%$ ), felt rested on waking $(47.0 \%$ versus $45.1 \%)$, were more active (37.0\% versus $35.8 \%)$, or felt better overall (48.1\% versus $50.0 \%$ ); these differences were not significant. Side-effects including daytime drowsiness (20.5\% versus $19.0 \%)$, headache $(18.1 \%$ versus $14.9 \%)$, dizziness (13.5\% versus $17.2 \%)$, difficulty concentrating $(16.7 \%$ versus $14.2 \%)$, or difficulty thinking (14.9\% versus $14.6 \%$ ), confusion (11.6 versus $7.8 \%)$, shaking $(9.2 \%$ versus $7.5 \%)$, and falls $(5.9 \%$ versus $7.8 \%$ ) were not significantly different between those on Z drugs or benzodiazepines (Appendix 1).

\section{DISCUSSION}

\section{Summary of main findings}

This study shows that in a sample of patients whose
Table 1. Demographic data for responders prescribed hypnotics for insomnia in the previous 6 months.

\begin{tabular}{|c|c|c|}
\hline Characteristics & ber $(n=705)$ & $(\%)$ \\
\hline \multicolumn{3}{|l|}{ Sex } \\
\hline Male & 223 & (31.6) \\
\hline Female & $379^{a}$ & (53.8) \\
\hline \multicolumn{3}{|l|}{ Age, years } \\
\hline $18-44$ & 69 & $(9.8)$ \\
\hline $45-64$ & 198 & 28.0) \\
\hline $65-84$ & 305 & (43.3) \\
\hline $85+$ & 51 & $(7.2)$ \\
\hline \multicolumn{3}{|l|}{ Responder } \\
\hline Patient & 618 & $(87.7)$ \\
\hline Relative & 46 & $(6.5)$ \\
\hline Carer & 19 & $(2.7)$ \\
\hline \multicolumn{3}{|l|}{ Medication type } \\
\hline Z drug & 370 & $(52.5)$ \\
\hline Benzodiazepine & 268 & (38.0) \\
\hline \multicolumn{3}{|l|}{ First prescriber } \\
\hline GP & 620 & (87.9) \\
\hline Psychiatrist & 53 & $(7.5)$ \\
\hline \multicolumn{3}{|l|}{ Advised duration of treatment } \\
\hline Days & 14 & $(2.0)$ \\
\hline Weeks & 30 & $(4.3)$ \\
\hline Months & 35 & $(5.0)$ \\
\hline Years & 28 & $(4.0)$ \\
\hline Indefinitely & 257 & $(36.4)$ \\
\hline Not advised & 298 & (42.3) \\
\hline \multicolumn{3}{|l|}{ Duration of treatment } \\
\hline 0-2 weeks & 13 & $(1.8)$ \\
\hline $2-3$ weeks & 11 & $(1.6)$ \\
\hline 4-52 weeks & 101 & (14.3) \\
\hline Over 1 year & 568 & $(80.6)$ \\
\hline \multicolumn{3}{|l|}{ Medication type } \\
\hline Repeat prescription & 649 & $(92.1)$ \\
\hline Acute (one-off) prescription & 48 & $(6.8)$ \\
\hline \multicolumn{3}{|l|}{ Frequency of taking medication } \\
\hline Daily & 475 & $(67.4)$ \\
\hline As needed & 222 & (31.5) \\
\hline \multicolumn{3}{|l|}{ Advised about side-effects } \\
\hline Yes & 301 & $(42.7)$ \\
\hline Not sure & 164 & (23.3) \\
\hline No & 213 & (30.2) \\
\hline \multicolumn{3}{|c|}{ Would like to come off medication } \\
\hline Yes & 131 & (18.6) \\
\hline No & 508 & (72.1) \\
\hline \multicolumn{3}{|l|}{ Tried to come off medication } \\
\hline Yes & 342 & $(48.5)$ \\
\hline No & 300 & (42.6) \\
\hline \multicolumn{3}{|l|}{ Dependency } \\
\hline Dependent & 323 & $(45.8)$ \\
\hline At risk of becoming dependent & 75 & (10.6) \\
\hline Not dependent & 247 & (35.0) \\
\hline \multicolumn{3}{|l|}{ Improvement in insomnia } \\
\hline Yes & 613 & $(87.0)$ \\
\hline No & 57 & $(8.1)$ \\
\hline
\end{tabular}

${ }^{a}$ Missing values account for totals less than 705 or $100 \%$.

GPs had prescribed hypnotics during the previous 6 months, there was no significant group difference in reported effectiveness or adverse reactions evoked by 


\begin{tabular}{|c|c|c|c|c|c|}
\hline & \multicolumn{2}{|c|}{$Z$ drug $^{a}$} & \multicolumn{2}{|c|}{ Benzodiazepine } & \multirow{2}{*}{$\frac{\chi^{2}}{P \text {-value }}$} \\
\hline & mber $(n=370)$ & $(\%)$ & Number $(n=268)$ & (\%) & \\
\hline \multicolumn{6}{|l|}{ Sex } \\
\hline Male & 122 & (33.0) & 77 & (28.7) & 0.23 \\
\hline Female & 198 & $(53.5)^{b}$ & 145 & $(54.1)$ & \\
\hline \multicolumn{6}{|l|}{ Age, years } \\
\hline $18-44$ & 42 & (11.4) & 22 & $(8.2)$ & 0.012 \\
\hline $45-64$ & 118 & (31.9) & 65 & (24.3) & \\
\hline $65-84$ & 147 & (39.7) & 120 & $(44.8)$ & \\
\hline $85+$ & 19 & $(5.1)$ & 27 & $(10.1)$ & \\
\hline \multicolumn{6}{|l|}{ First prescriber } \\
\hline GP & 320 & $(86.5)$ & 242 & $(90.3)$ & 0.027 \\
\hline Psychiatrist & 34 & $(9.2)$ & 13 & $(4.9)$ & \\
\hline \multicolumn{6}{|l|}{ Duration of treatment } \\
\hline Up to 4 weeks & 13 & (3.5) & 10 & $(3.7)$ & 0.27 \\
\hline 4-52 weeks & 64 & (17.3) & 32 & (11.9) & \\
\hline Over 1 year & 286 & (77.3) & 225 & $(84.0)$ & \\
\hline \multicolumn{6}{|l|}{ Medication type } \\
\hline Repeat prescription & 339 & (91.6) & 248 & (92.5) & 0.87 \\
\hline Acute (one-off) prescription & 24 & $(6.5)$ & 19 & $(7.1)$ & \\
\hline \multicolumn{6}{|l|}{ Frequency of taking medication } \\
\hline Daily & 246 & $(66.5)$ & 186 & $(69.4)$ & 0.41 \\
\hline As needed & 120 & $(32.4)$ & 79 & $(29.4)$ & \\
\hline \multicolumn{6}{|l|}{ Advised about side-effects } \\
\hline Yes & 157 & $(42.4)$ & 121 & $(45.1)$ & 0.54 \\
\hline Not sure & 92 & (24.9) & 57 & (21.2) & \\
\hline No & 108 & $(29.2)$ & 82 & $(30.6)$ & \\
\hline \multicolumn{6}{|c|}{ Would like to come off medication } \\
\hline Yes & 84 & (22.7) & 33 & (12.3) & $0.001^{c}$ \\
\hline No & 254 & $(68.6)$ & 211 & $(78.7)$ & \\
\hline \multicolumn{6}{|l|}{ Tried to come off medication } \\
\hline Yes & 194 & (52.4) & 110 & $(41.0)$ & $0.001^{c}$ \\
\hline No & 141 & $(38.1)$ & 137 & $(51.1)$ & \\
\hline \multicolumn{6}{|l|}{ Dependency } \\
\hline Dependent & 161 & $(43.5)$ & 126 & $(47.0)$ & 0.01 \\
\hline At risk of becoming dependent & 53 & (14.3) & 18 & $(6.7)$ & \\
\hline Not dependent & 125 & (33.8) & 101 & $(37.7)$ & \\
\hline \multicolumn{6}{|l|}{ Improvement in insomnia } \\
\hline Yes & 317 & $(85.7)$ & 239 & $(89.2)$ & 0.012 \\
\hline No & 39 & (10.5) & 13 & (14.5) & \\
\hline
\end{tabular}

${ }^{\mathrm{a} C}$ Comparisons include patients who confirmed that they were taking $Z$ drug or benzodiazepine. ${ }^{\mathrm{b}} \mathrm{Missing}$ values account for totals less than the stated denominator or $100 \% .{ }^{\circ} \mathrm{P}<0.01$.

Z drugs or benzodiazepine hypnotics. Adverse effects were common, affecting over two-fifths of those on either drug. Almost half the responders had tried to stop taking their medication, and this was more likely for those on Z drugs. Withdrawal effects were common, with almost one-quarter of those who had tried to discontinue the drug regime experiencing panic or other withdrawal symptoms. Almost one in five patients on either agent expressed a desire to come off hypnotic medication, and those on $\mathbf{Z}$ drugs were more likely to want to stop than those on benzodiazepines. Despite this, the majority of patients, whether on $Z$ drugs $(68.6 \% ; 254)$ or benzodiazepines $(78.7 \% ; 211)$, wished to continue taking this medication.

\section{Strengths and limitations of the study}

This study is the first to compare the experiences of those on $\mathrm{Z}$ drugs with those taking benzodiazepine hypnotics. The study surveyed a random sample of 705 patients from 32 general practices who had been prescribed hypnotics (at least one prescription) over the previous 6 months. The response rate to the survey was satisfactory for a self-administered postal survey of patients. The study was conducted within a single $\mathrm{PCT}$, and not all practices agreed to participate in the survey. Patients from practices that did participate may have had different experiences from those that did not. There may have been a higher response rate among patients on repeat prescriptions than among those 
Table 3. Logistic regression of clinical effects related to hypnotic type.

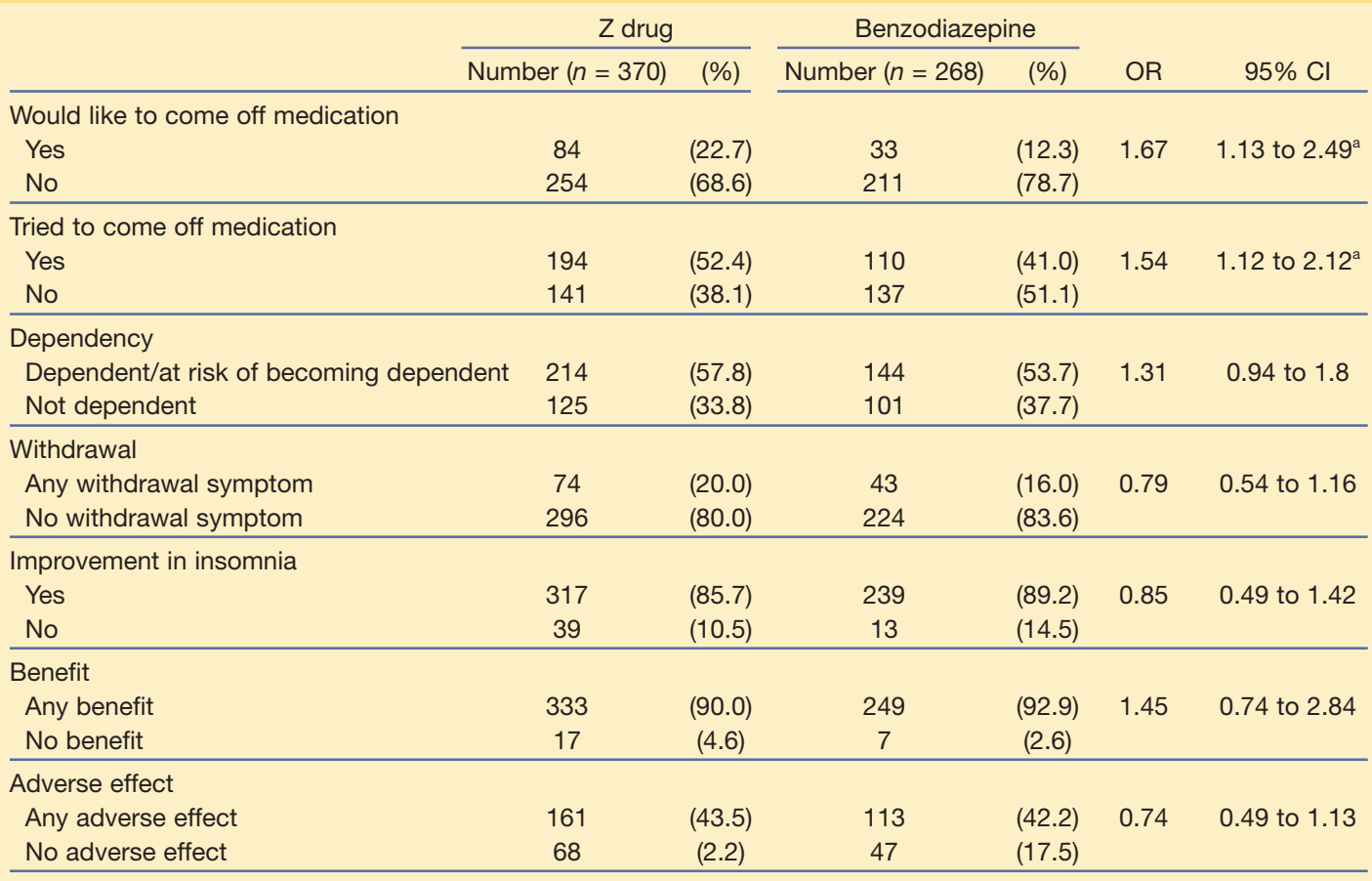

Backwards stepwise conditional regression using terms: medication type ( $Z$ drug or benzodiazepine hypnotic), sex (male or female), age group ( $\geq 75$ years), length of treatment ( $\geq 4$ weeks). Similar results were obtained using forward stepwise conditional regression. $O R=$ odds ratio. ${ }^{a} P<0.01$.

who only took hypnotics for a short time, although comparisons were adjusted for length of treatment.

There was no opportunity within this study design to survey non-responders. However, it is likely that response biases were similar for participants on Zdrug or benzodiazepine hypnotics; therefore, the group comparisons, in which logistic regression was used to account for age and sex of patients as well as duration of treatment, are likely to be valid.

\section{Comparison with existing literature}

Benzodiazepines and $Z$ drugs are known to be prescribed for longer than is recommended and in excessive doses, particularly in older adults:4,20 a finding that was confirmed in this study. Given that the incidence of insomnia tends to increase with age (at least until 80 years of age), that it is often chronic or recurrent, and that once started, hypnotics tend to continue being used in almost one-third of patients, an ageing population could lead to increased hypnotic prescribing in the long term. ${ }^{21}$

In a previous study it was shown that perceptions of GPs towards hypnotics tended to be in favour of newer hypnotics despite a lack of evidence showing benefit of newer $Z$ drugs compared to benzodiazepines. ${ }^{16}$ This may partly explain why $Z$ drugs have overtaken benzodiazepines as hypnotics of first choice, and why they were more likely to be prescribed for younger patients in this community study.
Although Z drugs have been promoted as being effective and safe, and compared favourably with benzodiazepines in terms of side-effect profile and dependence, ${ }^{22}$ these findings are not supported in this study. Reported rates of adverse reactions to $Z$ drugs were similar in nature and incidence to benzodiazepines in responders, and comparable with the findings of other studies in hospital settings. ${ }^{23}$ Cognitive problems ${ }^{24}$ and psychomotor impairment ${ }^{25}$ similar to those of benzodiazepines have also been demonstrated in other studies, and recent evidence suggests that $Z$ drugs may also increase the risk of depression. ${ }^{26}$

\section{Implications for future research and clinical practice}

Sleep problems are often chronic and therefore there is a mismatch with pharmacotherapy which is only suitable for the short term. ${ }^{27}$ This study supports the lack of demonstrable improved efficacy of $Z$ drugs, similar rates of adverse events, and the possibility of higher rates of dependence of $Z$ drugs compared to benzodiazepine hypnotics.

The lack of difference between these two types of drugs and the importance of restricting hypnotics for short-term use need to be emphasised to patients and practitioners. Hypnotic drugs continue to be prescribed instead of safer alternatives when they have not been shown to be superior to placebo in primary insomnia 
for improving function or quality of life. ${ }^{28}$ Their routine use is likely to reinforce help-seeking behaviour, ${ }^{29}$ involving further requests for hypnotic prescriptions.

Further research is recommended into the process that takes place during the consultation for sleep presentations. More research is needed using nonpharmacological approaches to insomnia, such as cognitive behavioural therapy which includes the techniques of sleep education, sleep hygiene, muscle relaxation, stimulus control, and sleep restriction. ${ }^{30,31}$ Research, including recent studies of cognitive behavioural therapy for insomnia in general practice, has demonstrated benefits in primary insomnia, and also in secondary insomnia due to physical disorders, such as painful conditions or psychological problems such as anxiety and depression. ${ }^{32,33}$

The findings point to a need for primary care service improvements that focus on helping patients stop their use of hypnotics as well as preventing their use as long-term treatments. This will need careful evaluation of evidence-based assessment tools and techniques applied to real-world primary care settings. ${ }^{34,35}$ Implementation will require commitment to change from patients, practitioners, and primary care organisations.

\section{Funding body}

Trent Research and Development Support Unit and the Health Foundation

\section{Ethical approval}

Lincolnshire Research Ethics Committee (04/Q2405/49)

\section{Competing interests}

The authors have stated that there are none

\section{Acknowledgements}

We thank GPs, the board, and executive of Lincolnshire Teaching Primary Care Trust for supporting this study. We are grateful to Professor Kevin Morgan for his comments on the paper, to Dr Ross Upshur who provided a copy of his questionnaire developed for another study, and to Martin Latham who supported the initial work for this study. This study forms part of a programme of research Resources for Effective Sleep Treatment (REST) supported by an Engaging in Quality in Primary Care award from the Health Foundation. Preliminary findings were presented at the Society of Academic Primary Care Annual Scientific Meeting in 2007

\section{Discuss this article}

Contribute and read comments about this article on the Discussion Forum: http://www.rcgp.org.uk/bjgp-discuss.

\section{REFERENCES}

1. Chevalier H, Los F, Boichut D, et al. Evaluation of severe insomnia in the general population: results of a European multinational survey. Psychopharmacol 1999; 13(4 Suppl 1): S21-S24.

2. Morphy H, Dunn KM, Lewis M, et al. Epidemiology of insomnia: a longitudinal study in a UK population. Sleep 2007; 30(3): 274-280.

3. Aikens JE, Rouse ME. Help-seeking for insomnia among adult patients in primary care. J Am Board Fam Pract 2005; 18(4): 257-261.

4. van der Hooft CS, Jong GW, Dieleman JP, et al. Inappropriate drug prescribing in older adults: the updated 2002 Beers criteria - a population-based cohort study. Br J Clin Pharmacol 2005; 60(2): 137-144.

5. Dundar Y, Boland A, Strobl J, et al. Newer hypnotic drugs for the shortterm management of insomnia: a systematic review and economic evaluation. Health Technol Assess 2004; 8(24): iii-x, 1-125.

6. Holbrook AM. Treating insomnia. BMJ 2004; 329(7476): 1198-1199.

7. Department of Health. Prescription costs analysis (2005). http://www.ic.nhs.uk/pubs/prescostanalysis2005 (accessed 1 May 2008).

8. National Statistics Online. Population change. Newport: National Office of Statistics, 2007. http://www.statistics.gov.uk/cci/nugget.asp?id=950 (accessed 6 May 2008).

9. Barnas $\mathrm{C}$, Fleischhacker WW, Whitworth $\mathrm{AB}$, et al. Characteristics of benzodiazepine long-term users: investigation of benzodiazepine consumers among pharmacy customers. Psychopharmacology (Berl) 1991; 103(2): 233-239.

10. King MB, Gabe J, Williams P, Rodrigo EK. Long term use of benzodiazepines: the views of patients. Br J Gen Pract 1990; 40(334): 194-196.

11. Lyndon RW, Russell JD. Benzodiazepine use in a rural general practice population. Aust N Z J Psychiatry 1988; 22(3): 293-298.

12. Bjorner T, Laerum E. Factors associated with high prescribing of benzodiazepines and minor opiates. A survey among general practitioners in Norway. Scand J Prim Health Care 2003; 21(2): 115-120.

13. Hamilton IJ, Reay LM, Sullivan FM. A survey of general practitioners' attitudes to benzodiazepine overprescribing. Health Bull (Edinb) 1990; 48(6): 299-303.

14. Mah L, Upshur RE. Long term benzodiazepine use for insomnia in patients over the age of 60: discordance of patient and physician perceptions. BMC Fam Pract 2002; 3: 9.

15. Iliffe S, Curran HV, Collins R, et al. Attitudes to long-term use of benzodiazepine hypnotics by older people in general practice: findings from interviews with service users and providers. Aging Ment Health 2004; 8(3): 242-248

16. Siriwardena AN, Qureshi Z, Gibson S, et al. GPs' attitudes to benzodiazepine and 'Z-drug' prescribing: a barrier to implementation of evidence and guidance on hypnotics. Br J Gen Pract 2006; 56(533): of evidence

17. Dundar Y, Dodd S, Strobl J, et al. Comparative efficacy of newer hypnotic drugs for the short-term management of insomnia: a systematic review and meta-analysis. Hum Psychopharmacol 2004 19(5): 305-322.

18. Barker MJ, Greenwood KM, Jackson M, Crowe SF. Persistence of cognitive effects after withdrawal from long-term benzodiazepine use: meta-analysis. Arch Clin Neuropsychol 2004; 19(3): 437-454.

19. Glass J, Lanctot KL, Herrmann N, et al. Sedative hypnotics in older people with insomnia: meta-analysis of risks and benefits. BMJ 2005 331(7531): 1169.

20. [No authors listed]. What's wrong with prescribing hypnotics? Drug Ther Bull 2004; 42(12): 89-93.

21. Morgan K, Clarke D. Longitudinal trends in late-life insomnia: implications for prescribing. Age Ageing 1997; 26(3): 179-184.

22. Hajak G, Muller WE, Wittchen HU, et al. Abuse and dependence potential for the non-benzodiazepine hypnotics zolpidem and zopiclone: a review of case reports and epidemiological data. Addiction 2003; 98(10): 1371-1378

23. Mahoney JE, Webb MJ, Gray SL. Zolpidem prescribing and adverse drug reactions in hospitalized general medicine patients at a Veterans Affairs hospital. Am J Geriatr Pharmacother 2004; 2(1): 66-74.

24. Pompeia S, Lucchesi LM, Bueno OF, et al. Zolpidem and memory: a study using the process-dissociation procedure. Psychopharmacology (Berl) 2004; 174(3): 327-333.

25. Vermeeren A. Residual effects of hypnotics: epidemiology and clinical implications. CNS Drugs 2004; 18(5): 297-328.

26. Kripke DF. Greater incidence of depression with hypnotic use than with placebo. BMC Psychiatry 2007; 7: 42.

27. Morgan K. New theories for older problems. Sleep Med Rev 2006; 10(4): 211-213.

28. Holbrook AM, Crowther R, Lotter A, et al. Meta-analysis of benzodiazepine use in the treatment of insomnia. CMAJ 2000; 162(2): 225-233.

29. Stott NC, Davis RH. The exceptional potential in each primary care consultation. J R Coll Gen Pract 1979; 29(201): 201-205.

30. Montgomery P, Dennis J. A systematic review of non-pharmacological therapies for sleep problems in later life. Sleep Med Rev 2004; 8(1): 47-62.

31. Morin CM, Hauri PJ, Espie CA, et al. Nonpharmacologic treatment of chronic insomnia. An American Academy of Sleep Medicine review. Sleep 1999; 22(8): 1134-1156.

32. Lichstein KL, Wilson NM, Johnson CT. Psychological treatment of secondary insomnia. Psychol Aging 2000; 15(2): 232-240.

33. Espie CA, MacMahon KM, Kelly HL, et al. Randomized clinical effectiveness trial of nurse-administered small-group cognitive behavio therapy for persistent insomnia in general practice. Sleep 2007; 30(5): 574-584.

34. Petit L, Azad N, Byszewski A, et al. Non-pharmacological management of primary and secondary insomnia among older people: review of assessment tools and treatments. Age Ageing 2003; 32(1): 19-25.

35. Sateia MJ, Nowell PD. Insomnia. Lancet 2004; 364(9449): 1959-1973. 


\section{Appendix 1. Patients' perceptions of benefits and disadvantages of $Z$ drugs and benzodiazepines.}

\begin{tabular}{|c|c|c|c|c|c|c|c|}
\hline & \multicolumn{3}{|c|}{$Z$ drugs $(n=370)$} & \multicolumn{3}{|c|}{ Benzodiazepine $(n=268)$} & \multirow[b]{2}{*}{$\begin{array}{l}\chi^{2} \text { test, } \\
P \text {-value }\end{array}$} \\
\hline & $\begin{array}{c}\text { Agree or } \\
\text { strongly agree, } \\
n(\%)\end{array}$ & $\begin{array}{c}\text { Not sure, } \\
n(\%)\end{array}$ & $\begin{array}{c}\text { Disagree or } \\
\text { strongly disagree, } \\
n(\%)\end{array}$ & $\begin{array}{c}\text { Agree or } \\
\text { strongly agree, } \\
n(\%)\end{array}$ & $\begin{array}{c}\text { Not sure, } \\
n(\%)\end{array}$ & $\begin{array}{c}\text { Disagree or } \\
\text { strongly disagree, } \\
n(\%)\end{array}$ & \\
\hline \multicolumn{8}{|l|}{ Perception of associated benefits } \\
\hline I take less time to get to sleep ${ }^{a}$ & $282(76.2)$ & $19(5.1)$ & $16(4.3)$ & $212(79.1)$ & $12(4.5)$ & $10(3.7)$ & 0.82 \\
\hline I wake less during the night & $225(60.8)$ & $25(6.8)$ & $37(10.0)$ & $149(55.6)$ & $22(8.2)$ & $28(10.4)$ & 0.61 \\
\hline I sleep longer overall & $180(48.6)$ & $37(10.0)$ & $54(14.5)$ & $128(47.8)$ & $18(6.7)$ & $42(15.7)$ & 0.38 \\
\hline I feel rested on waking up & $174(47.0)$ & $53(14.3)$ & $51(13.8)$ & $121(45.1)$ & $36(13.4)$ & $34(12.7)$ & 0.98 \\
\hline I am more active during the day & $137(37.0)$ & $68(18.4)$ & $50(13.5)$ & $96(35.8)$ & $38(14.2)$ & 49 (18.3) & 0.14 \\
\hline I feel better overall & $178(48.1)$ & 64 (17.3) & $38(10.3)$ & $134(50.0)$ & $38(14.2)$ & $26(9.7)$ & 0.59 \\
\hline \multicolumn{8}{|l|}{ Perception of associated side-effects } \\
\hline Headaches & $67(18.1)$ & $26(7.0)$ & $140(37.8)$ & $40(14.9)$ & $12(4.5)$ & $108(40.3)$ & 0.27 \\
\hline Dizziness & $50(13.5)$ & $24(6.5)$ & $148(40.0)$ & $46(17.2)$ & $13(4.9)$ & $109(40.7)$ & 0.38 \\
\hline Sickness & $22(5.9)$ & $16(4.3)$ & $163(44.1)$ & $18(6.7)$ & $9(3.4)$ & $120(44.8)$ & 0.77 \\
\hline Drowsiness (during the daytime) & $76(20.5)$ & $28(7.6)$ & $132(35.7)$ & $51(19.0)$ & $13(4.9)$ & $95(35.4)$ & 0.48 \\
\hline Difficulty thinking & 55 (14.9) & $29(7.8)$ & $142(38.4)$ & $39(14.6)$ & $9(3.4)$ & $108(40.3)$ & 0.073 \\
\hline Difficulty concentrating & $62(16.7)$ & $29(7.8)$ & $144(38.9)$ & $40(14.9)$ & $14(5.2)$ & $102(38.1)$ & 0.54 \\
\hline Falls & $22(5.9)$ & $12(3.2)$ & $176(47.6)$ & $21(7.8)$ & $5(1.9)$ & $122(45.5)$ & 0.37 \\
\hline Fractures & $6(1.6)$ & $10(2.7)$ & $187(50.5)$ & $12(4.5)$ & $5(1.9)$ & $126(47.0)$ & 0.07 \\
\hline Road traffic accidents & $5(1.4)$ & $8(2.2)$ & $190(51.4)$ & $4(1.5)$ & $3(1.1)$ & $130(48.5)$ & 0.65 \\
\hline Visual disturbance & $23(6.2)$ & $20(5.4)$ & $165(44.6)$ & $16(6.0)$ & $9(3.4)$ & 116 (43.3) & 0.56 \\
\hline Shaking & $34(9.2)$ & $16(4.3)$ & $157(42.4)$ & $20(7.5)$ & $11(4.1)$ & $114(42.5)$ & 0.79 \\
\hline
\end{tabular}

aMissing values account for totals less than 370 or 268. 